\title{
Research on Energy Efficiency of Typical Construction Equipment for Transmission Lines in Tibet
}

\author{
XIA Yongjun ${ }^{1}$ and ZHAO Fei ${ }^{1, \text { a }}$ \\ ${ }^{1}$ China Electric Power Research Institute, Haidian District, Beijing 100192, China
}

\begin{abstract}
The construction of transmission line in Tibet high altitude area has the characteristics of low pressure, low oxygen and low temperature. In the special environmental condition, the transmission line construction equipment with engine as the power source is highly effective, which affects the efficiency and safety of construction[1].The experimental study on engineering mechanical industry plateau transmission line is still in the blank stage,thus relying on the Tibet networking project selects 5 different high altitude test points to plateau $500 \mathrm{kV}$ transmission line construction commonly used types of pullers, tensioners and powered winch as an object of study to carry out the typical construction equipment energy efficiency test of field measurements effective output power equipment in different altitude environment from the perspective of practical application and analysis of law and effect mechanism of falling equipment.
\end{abstract}

\section{Introduction}

The Tibet area has a special environment with high altitude, high cold, anoxia and so on. The bad construction conditions cause the engineering construction personnel and the machinery to reduce the efficiency seriously. With the increase of EHV power transmission project construction projects in Tibet area, $500 \mathrm{kV}$ transmission line voltage will gradually become the backbone network in Tibet power grid, the special construction environment, increase construction quantity and construction workers in the Tibet area that will be more dependent on machinery[2]. Therefore, in the Tibet area to carry out research on typical construction equipment adaptability, analysis of its height decreases and regularity of effect mechanism in different altitude, and puts forward some concrete measures for typical construction equipment and reduce efficiency reduction principle, equipment capacity, construction personnel can reduce the labor intensity and improve the construction efficiency for future power grid construction in high altitude area to give full play to.

\section{Test situation}

\subsection{Test object and method}

\footnotetext{
${ }^{\mathrm{a}}$ Corresponding author : 316970757@qq.com
} 
The energy efficiency test of the typical construction equipment is aimed at the environmental characteristics of the high altitude environment in Tibet, and carries out the research on the pullers, tensioners and powered winch application with the engine as the power source in the transmission line construction equipment.The experimental research samples are commonly used in the $500 \mathrm{kV}$ transmission line projects in Tibet area, such as pullers, tensioners and powered winch as the research sample [3], the details are shown in Table 1.

Table 1. Test sample table

\begin{tabular}{|c|c|c|c|}
\hline Name & Model & Rated load & Rated speed \\
\hline The pullers & SA-QY-250 & $250 \mathrm{kN}$ & $2.4 \mathrm{~km} / \mathrm{h}$ \\
\hline The tensioners & SA-ZY-2 $\times 40$ & $2 \times 40 \mathrm{kN}$ & $2.5 \mathrm{~km} / \mathrm{h}$ \\
\hline The powered winch & CJM-5 & $50 \mathrm{kN}$ & $0.066 \mathrm{~m} / \mathrm{s}$ \\
\hline
\end{tabular}

The typical construction equipment efficiency test method is to use the test sample equipment as the traction terminal, the auxiliary equipment as the braking terminal to pull through the wire rope, the test layout is shown in Figure 1 to 3, and the test condition is shown in Table 2. The test is carried out by using the sample machine to drive the auxiliary machinery at the maximum speed at the same load and engine speed. At the same time, the dynamic wireless sensor and the wire rope speed measuring device are used to record the tension and speed data during the whole test.

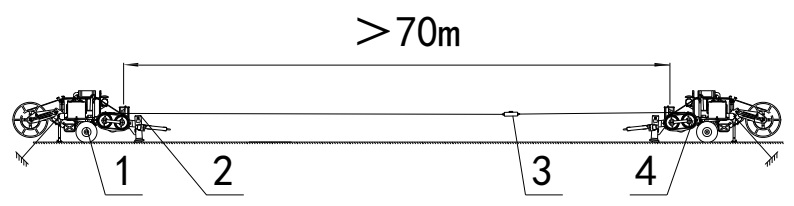

1-sample pullers; 2 -speed measuring device; 3 -dynamic tension sensor; 4-auxiliary puller

Figure 1. Schematic diagram of energy efficiency test for pullers

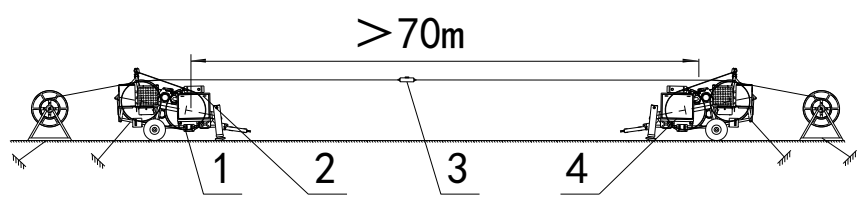

1-sample tensioners; 2-speed measuring device; 3 -dynamic tension sensor; 4-auxiliary tensioners

Figure 2. Schematic diagram of energy efficiency test for tensioners

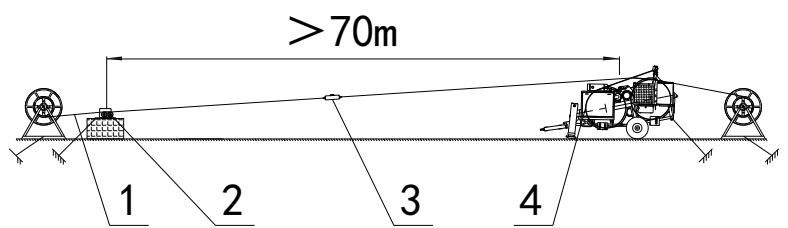

1-speed measuring device; 2-sample powered winch; 3-dynamic tension sensor; 4-auxiliary tensioners

Figure 3. Schematic diagram of energy efficiency test for powered winch 
Table 2. Test condition table

\begin{tabular}{|c|c|c|c|}
\hline \multirow{2}{*}{$\begin{array}{l}\text { Serial } \\
\text { number }\end{array}$} & \multirow{2}{*}{ Test sample } & \multicolumn{2}{|c|}{ Test condition } \\
\hline & & Engine speed & Test load \\
\hline \multirow{2}{*}{1} & \multirow{2}{*}{$\begin{array}{l}\text { The puller of } \\
\text { SA-QY-250 }\end{array}$} & $1500 \mathrm{rpm}$ & $150 \mathrm{kN}$ \\
\hline & & $1500 \mathrm{rpm}$ & $175 \mathrm{kN}$ \\
\hline \multirow{2}{*}{2} & \multirow{2}{*}{$\begin{array}{l}\text { The tensioner of } \\
\text { SA-ZY- } 2 \times 40\end{array}$} & 1500rpm & $24 \mathrm{kN}($ reverse $)$ \\
\hline & & $1500 \mathrm{rpm}$ & $28 \mathrm{kN}($ reverse $)$ \\
\hline \multirow{2}{*}{3} & \multirow{2}{*}{$\begin{array}{c}\text { The powered winch } \\
\text { of CJM } 5\end{array}$} & I gear & $30 \mathrm{kN}$ \\
\hline & & I gear & $35 \mathrm{kN}$ \\
\hline
\end{tabular}

\subsection{Test implementation}

Select 5 different high altitudes test points as the data acquisition point in the area of Tibet [4]; select 1 plain test points as a reference point in Zhengzhou. The typical construction equipment efficiency test were carried out a total of 6 test points, the scene is shown in Figure 4, the specific implementation place as shown in table 3.

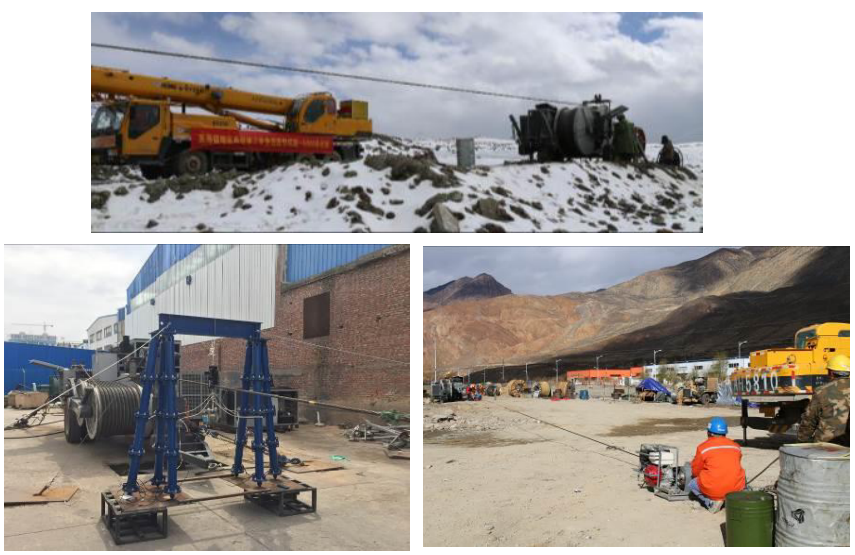

Figure 4. Field test photo of typical construction equipment

Table 3. Test implement site table

\begin{tabular}{|c|c|c|}
\hline $\begin{array}{c}\text { Serial } \\
\text { number }\end{array}$ & Position & $\begin{array}{c}\text { Actual } \\
\text { altitude }\end{array}$ \\
\hline 1 & Reference point & $162 \mathrm{~m}$ \\
\hline 2 & Test point near $3300 \mathrm{~m}$ & $3313 \mathrm{~m}$ \\
\hline 4 & Test point near $3700 \mathrm{~m}$ & $3740 \mathrm{~m}$ \\
\hline 5 & Test point near $4100 \mathrm{~m}$ & $4147 \mathrm{~m}$ \\
\hline 6 & Test point near $4500 \mathrm{~m}$ & $4553 \mathrm{~m}$ \\
\hline 7 & Test point near $4900 \mathrm{~m}$ & $4990 \mathrm{~m}$ \\
\hline
\end{tabular}




\section{Test result}

\subsection{Data processing method}

The data collected by the dynamic wireless tension sensor and the wire rope speed measuring device used during the test are all the database with frequency of $5 \mathrm{~Hz}$. The tension time curve and the speed time curve are drawn into two databases, and the two curves are compared by the time zero point reclosed.From the whole process of the test selection of tension relatively stable and relatively stable period of time speed as the effective time period, as shown in Figure 5.

The data in the effective time segment is calculated according to the power point formula, and the average value of all data points in the effective time period is taken as the last effective output power [5], as shown in Figure 6.

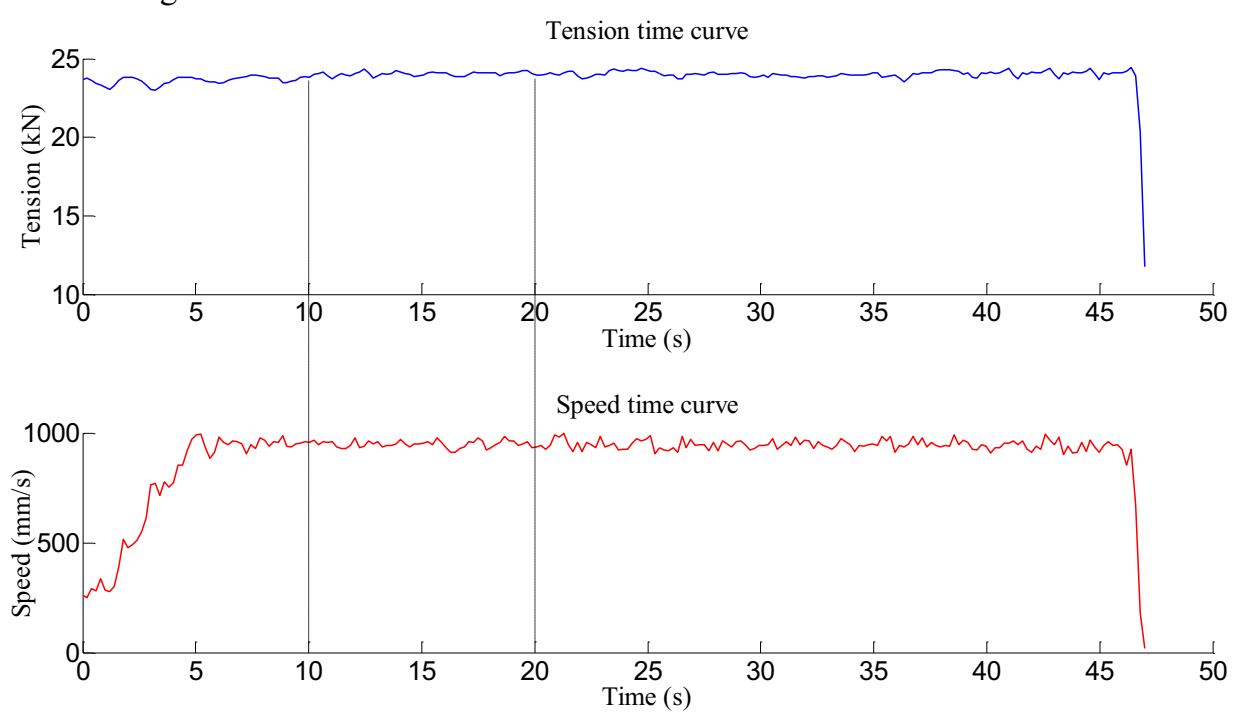

Figure 5. $24 \mathrm{kN}$ working condition data curve of tensioners at altitude $162 \mathrm{~m}$

Power time curve(10s - 20s)

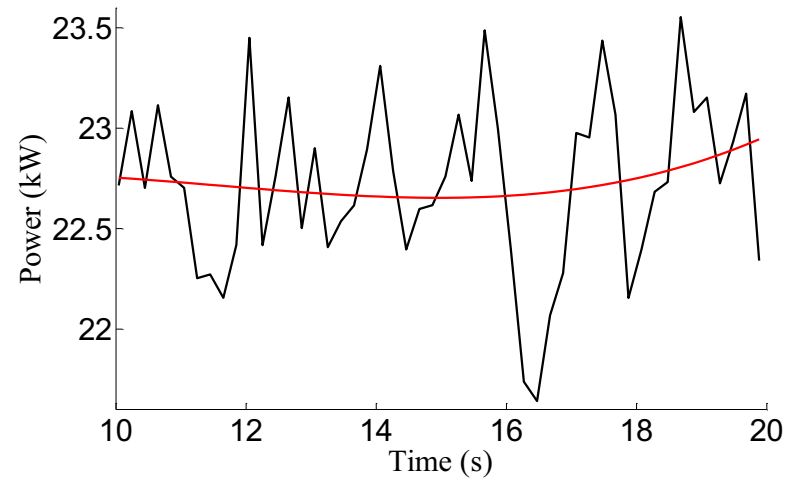

Figure 6. Power-time curve in effective time period

$$
\begin{aligned}
& \text { - Mean value: } 22.7212 \\
& \text { — Fitting curve }
\end{aligned}
$$

\subsection{Data results}

A summary of the effective output power collation of 6 test points is summarized as shown in Table 4 . 
Table 4. Summary table of effective output power of typical construction equipment

\begin{tabular}{|c|c|c|c|c|c|c|c|}
\hline \multirow{2}{*}{ Working condition } & \multicolumn{6}{|c|}{ Effective output power at the altitude test point(kW) } \\
\cline { 3 - 8 } & $\mathbf{1 6 2 m}$ & $\mathbf{3 3 1 3} \mathbf{m}$ & $\mathbf{3 7 4 0}$ & $\mathbf{4 1 4 7} \mathbf{m}$ & $\mathbf{4 5 5 3 m}$ & $\mathbf{4 9 9 0 m}$ \\
\hline \multirow{3}{*}{ The pullers } & $175 \mathrm{kN}$ & 166.578 & 161.724 & 153.939 & 151.775 & 146.092 & 139.937 \\
\cline { 2 - 8 } & $150 \mathrm{kN}$ & 146.954 & 129.567 & 128.725 & 125.232 & 122.821 & 114.250 \\
\hline \multirow{2}{*}{$\begin{array}{c}\text { The } \\
\text { tensioners }\end{array}$} & $28 \mathrm{kn}$ & 26.036 & 22.146 & 19.679 & 19.470 & 18.769 & 18.617 \\
\cline { 2 - 8 } & $24 \mathrm{kn}$ & 22.721 & 19.454 & 18.583 & 17.860 & 17.052 & 17.021 \\
\hline $\begin{array}{c}\text { The } \\
\text { powered } \\
\text { winch }\end{array}$ & $35 \mathrm{kN}$ & 2.781 & 2.652 & 2.507 & 2.262 & 2.107 & 1.787 \\
\cline { 2 - 8 } & $30 \mathrm{kN}$ & 2.552 & 2.296 & 2.229 & 2.087 & 1.838 & 1.672 \\
\hline
\end{tabular}

From table 4, it can be seen that the effective output power of the typical construction equipment is gradually reduced with the elevation of the altitude test points.

\section{Result analysis}

The test results of high altitude test are compared with the results of the benchmark datum in the plain. The average reduction range of different load cases is used to reflect the descending effect of the typical construction equipment at the altitude test point. It is summarized and summarized as shown in Table 5, and is drawn up and made into a chart as shown in Figure 7.

Table 5. Energy efficiency scale table of typical construction equipment

\begin{tabular}{|c|c|c|c|}
\hline Altitude & The pullers & The tensioners & The powered winch \\
\hline $3313 \mathrm{~m}$ & $7.37 \%$ & $14.66 \%$ & $7.32 \%$ \\
\hline $3740 \mathrm{~m}$ & $10.00 \%$ & $21.31 \%$ & $11.24 \%$ \\
\hline $4147 \mathrm{~m}$ & $11.83 \%$ & $23.31 \%$ & $18.43 \%$ \\
\hline $4553 \mathrm{~m}$ & $14.36 \%$ & $26.43 \%$ & $26.09 \%$ \\
\hline $4990 \mathrm{~m}$ & $19.12 \%$ & $26.79 \%$ & $35.11 \%$ \\
\hline
\end{tabular}

In typical construction equipment samples, the engine of traction and tension machine is a diesel engine with turbocharger, and the motor form of engine is a turbocharger diesel engine.

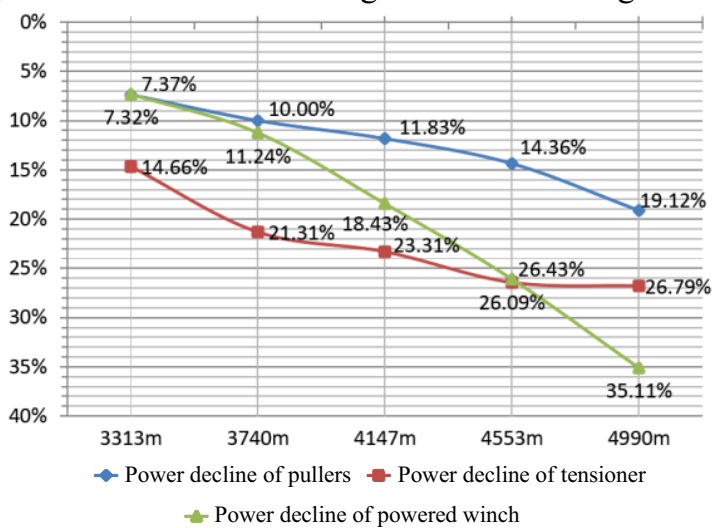

Figure 7. Reduced efficiency curve diagram of energy test of typical construction equipment 


\section{Conclusion}

The adaptability of typical construction equipment is studied based on the Tibet Internet project. The eff effective output power of the typical equipment is taken as the research object, and the effective output power of the equipment is measured:

(1) The typical construction equipment energy efficiency test results representation in the special environment of Tibet low, hypoxia and low temperature, choose to adapt to the harsh construction environment to maintain a certain amount of reserve power construction equipment can be better with a turbocharged engine and use conditions.

(2) Under the restriction of construction hardware conditions, we can also take the efficiency reduction test curve of typical construction equipment in Figure 7 as reference for selection, and consider the factors such as old equipment, engine calibration power and other factors.

(3) In the research and design of special plateau type construction equipment, it is recommended to consider comprehensively from two aspects of engine power margin and practical measures, and enhance the applicability of equipment through overall design accounting.

\section{Acknowledgements}

This research was support by Science and Technology Research Project of State Grid(Research on technical standardization of ultra high altitude EHV and super high difference power grid construction)

\section{References}

1. YIN Dengfeng, ZHOU Hongbing, HAO Peng. Computer Simulation. Forecast and analysis for diesel engine plateau performance of engineering machinery. 2014 (2014. 09): 422-426.

2. SHEN Weichun,TIAN Jinbu,ZHANG Tianwen, et al. Power Technology.Study on the efficienty reduction of artificial labor in Tibet power grid. (1674-4586), 2010 (9).

3. YU Qihao,LIU Houxiong, QIAN Jin, et al. Journal of Engineering Geophysics. Analysis on the engineering problem of the $\pm 500 \mathrm{kV}$ transmission line of the Qinghai Tibet direct currentnetwork. 2009, 6(6): 806-812.

4. DONG Hongyu. Industrial Technology in Shandong. Analysis of construction machinery reduction efficiency in power grid engineering in alpine area. 2015 (19): 92-92.

5. SUN Miaomiao, ZHAO Jinliang, LI Xiuzhi, et al. Electronic Test. Countermeasures for the use of low temperature environment of lead acid battery. 2016 (7X): 165. 